\title{
Evaluation of the Privacy Risks of Personal Health Identifiers and Quasi-Identifiers in a Distributed Research Network: Development and Validation Study
}

SeHee $\mathrm{Oh}^{1}$, BS; MinDong Sung ${ }^{1}$, MD; Yumie Rhee ${ }^{2}$, PhD; Namki Hong ${ }^{2}$, MD; Yu Rang Park ${ }^{1}$, PhD

${ }^{1}$ Department of Biomedical Systems Informatics, Yonsei University College of Medicine, Seoul, Republic of Korea

${ }^{2}$ Department of Internal Medicine, Endocrine Research Institute, Yonsei University College of Medicine, Seoul, Republic of Korea

Corresponding Author:

Yu Rang Park, PhD

Department of Biomedical Systems Informatics

Yonsei University College of Medicine

50 Yonsei-ro

Seodaemun-gu

Seoul, 03722

Republic of Korea

Phone: 82222282493

Email: yurangpark@yuhs.ac

\section{Abstract}

Background: Privacy should be protected in medical data that include patient information. A distributed research network (DRN) is one of the challenges in privacy protection and in the encouragement of multi-institutional clinical research. A DRN standardizes multi-institutional data into a common structure and terminology called a common data model (CDM), and it only shares analysis results. It is necessary to measure how a DRN protects patient information privacy even without sharing data in practice.

Objective: This study aimed to quantify the privacy risk of a DRN by comparing different deidentification levels focusing on personal health identifiers (PHIs) and quasi-identifiers (QIs).

Methods: We detected PHIs and QIs in an Observational Medical Outcomes Partnership (OMOP) CDM as threatening privacy, based on 18 Health Insurance Portability and Accountability Act of 1996 (HIPPA) identifiers and previous studies. To compare the privacy risk according to the different privacy policies, we generated limited and safe harbor data sets based on 16 PHIs and 12 QIs as threatening privacy from the Synthetic Public Use File 5 Percent (SynPUF5PCT) data set, which is a public data set of the OMOP CDM. With minimum cell size and equivalence class methods, we measured the privacy risk reduction with a trust differential gap obtained by comparing the two data sets. We also measured the gap in randomly sampled records from the two data sets to adjust the number of PHI or QI records.

Results: The gaps averaged $31.448 \%$ and $73.798 \%$ for PHIs and QIs, respectively, with a minimum cell size of one, which represents a unique record in a data set. Among PHIs, the national provider identifier had the highest gap of $71.236 \%(71.244 \%$ and $0.007 \%$ in the limited and safe harbor data sets, respectively). The maximum size of the equivalence class, which has the largest size of an indistinguishable set of records, averaged 771. In 1000 random samples of PHIs, Device_exposure_start_date had the highest gap of $33.730 \%$ (87.705\% and 53.975\% in the data sets). Among QIs, Death had the highest gap of $99.212 \%$ (99.997\% and $0.784 \%$ in the data sets). In 1000, 10,000, and 100,000 random samples of QIs, Device_treatment had the highest gaps of $12.980 \%$ (99.980\% and $87.000 \%$ in the data sets), $60.118 \%(99.831 \%$ and $39.713 \%)$, and $93.597 \%(98.805 \%$ and $5.207 \%)$, respectively, and in 1 million random samples, Death had the highest gap of $99.063 \%$ (99.998\% and $0.934 \%$ in the data sets).

Conclusions: In this study, we verified and quantified the privacy risk of PHIs and QIs in the DRN. Although this study used limited PHIs and QIs for verification, the privacy limitations found in this study could be used as a quality measurement index for deidentification of multi-institutional collaboration research, thereby increasing DRN safety.

(JMIR Med Inform 2021;9(5):e24940) doi: 10.2196/24940 


\section{KEYWORDS}

distributed research network; Observational Medical Outcomes Partnership common data model; privacy risk quantification; personal health identifier; quasi-identifier

\section{Introduction}

As medical data include sensitive personal patient information, various challenges are being studied to protect patient information and optimize research results, including artificial intelligence, federated learning, and distributed research networks (DRNs) [1-11]. Among the above challenges, the DRN is a multi-institutional collaboration network [1] for standardizing the data of participating institutions into a common structure, terminology, and software called a common data model (CDM) [12-16]. In such research networks, data are not shared directly, and only analysis results are shared [1,3,6,17]. In research where sharing sensitive patient information has limitations or where large-scale data privacy needs to be preserved, the DRN structure is applied to standardize the data, terminology, and software [4-6]. There are several CDMs in DRNs, including the Observational Medical Outcomes Partnership (OMOP) CDM of Observational Health Data Sciences and Informatics (OHDSI), Sentinel CDM of the Food and Drug Administration, and Patient - Centered Outcomes Research Network of the Patient-Centered Outcomes Research Institute [18,19].

A DRN was recently recognized as a platform for protecting large-scale data [16,20-22]. DRN-based studies have argued two factors that enable the DRN infrastructure to mitigate privacy issues relative to other data sharing-based studies [1,6,23-29]. First, a DRN process protects patient information without directly sharing data $[1,3,6,17]$. Second, a CDM structure excludes some direct identifiers that could threaten the privacy of patient information, such as names and exact birthdays, by complying with the Health Insurance Portability and Accountability Act (HIPAA) [30-33]. Therefore, a DRN protects patient information through processes and structures.

However, previous studies have revealed limitations of DRNs in terms of data privacy. First, a DRN in a single site has privacy issues similar to a conventional database owing to repeated reuse [34-41]. Second, DRN privacy may be threatened when the remaining age and local information are used, even if direct identifiers are removed [34-43]. DRN researchers have recognized that there are no satisfactory solutions to privacy risk [43]. Despite such privacy risks, few studies have objectively measured these risks as compared to conventional data sharing-based studies [44-46]. To mitigate the possible risk to a DRN, an objective measurement of the privacy risk should be performed.
Thus, this study aimed to quantify DRN privacy risk by comparing different deidentification levels focusing on personal health identifiers (PHIs) and quasi-identifiers (QIs) of patient information. The key research questions in this study are as follows: (1) What PHIs and QIs are included in a DRN, and how many exist? (2) Using a PHI and QI, when comparing the deidentification level of a CDM to a safe harbor policy, how much will be the decrease in the DRN privacy risk? and (3) What is the true privacy risk of the PHI or QI itself when adjusted for the number of records?

\section{Methods}

\section{Data Sources}

We used the Synthetic Public Use File 5 Percent (SynPUF5PCT) data set, which is a sample data set of the OMOP CDM. The OMOP CDM (version 5.2.2), which was developed by OHDSI $[18,47]$, is a database of relational schema and consists of 37 tables with demographic information, disease natural history, health care cost, etc [48]. The SynPUF5PCT is a synthetic data set with 5\% random sampling from a synthetic public use file of the Centers for Medicare and Medicaid Services [49] and complies with the limited data set policy of the HIPAA [32]. The SynPUF5PCT consists of 33 of 37 OMOP CDM tables and is provided from the OHDSI [50]. We used only 12 tables with patient information without missing and null variables from the SynPUF5PCT [51].

\section{Target PHIs and QIs}

In this study, PHIs and QIs were focused on as privacy-threatening patient information by referencing previous studies [52-54]. For the PHIs, we manually matched the structure of the OMOP CDM based on 18 HIPAA identifiers (Figure 1) [55]. For the QIs, we selected the target range in demographic variables (eg, year of birth and gender) and clinical variables (eg, clinical order code) based on previous studies on the privacy risk of QIs [52-54,56,57]. In the 18 HIPAA identifiers, however, dates (excluding the year) and zip codes are defined as PHIs with a QI characteristic [56]. We prioritized the 18 HIPAA identifiers and fixed the dates and zip codes as PHIs instead of QIs. Forty-five PHIs and 17 QIs were detected from the OMOP CDM structure (Multimedia Appendix 1) [58]. Because there were missing tables in the SynPUF5PCT compared to the OMOP CDM, 16 PHIs and 12 QIs were targeted from the SynPUF5PCT (Figure 1 and Table 1). Detailed information for the 28 targeted variables is presented in Multimedia Appendix 2 . 
Figure 1. Study workflow. PHI: personal health identifier; QI: quasi-identifier.

Match the structure of Observational Medical Outcomes Partnerships Common Data Model to the 18 Health Insurance Portability and Accountability Act identifiers

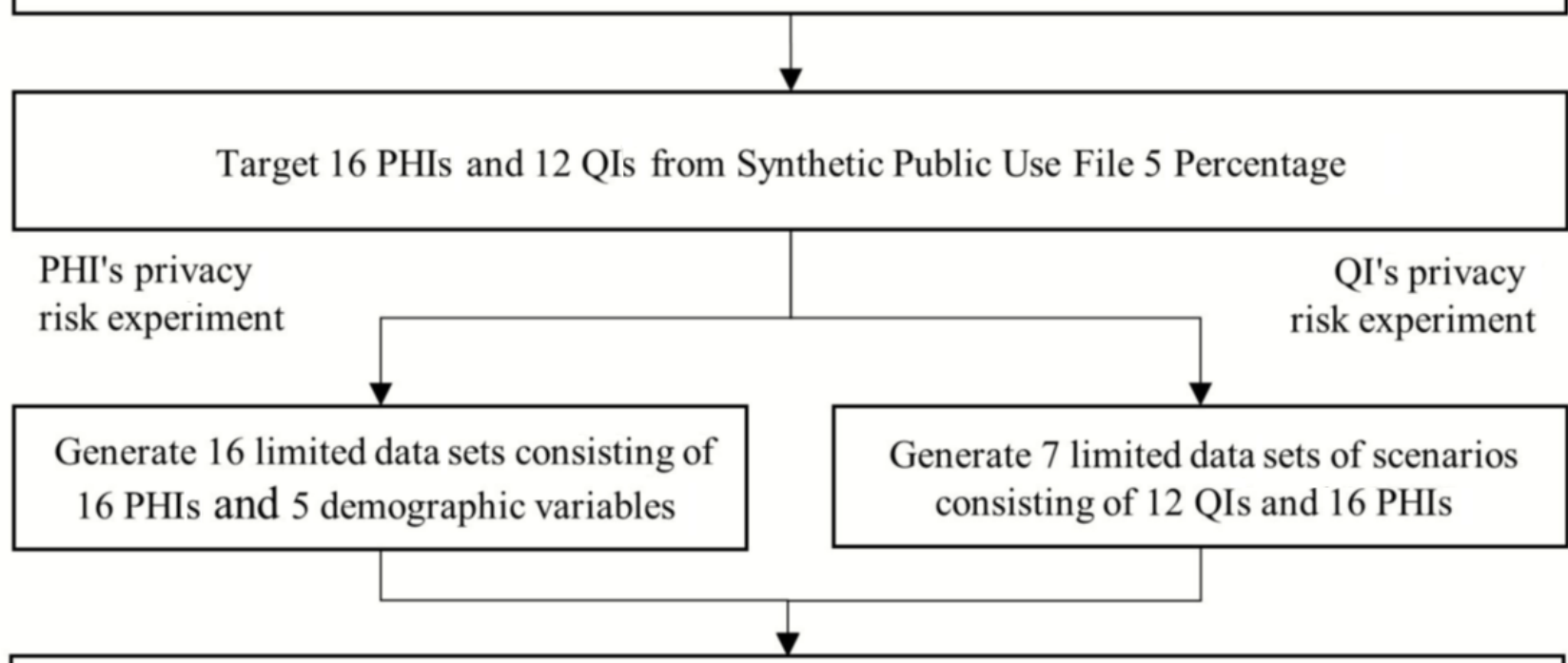

Apply safe harbor policy to each limited data set and generate a safe harbor data set

Generate 16 safe harbor data sets


Table 1. Sixteen personal health identifiers and 12 quasi-identifiers targeted in the Observational Medical Outcomes Partnership common data model based on not null values in the Synthetic Public Use File 5 Percent data set.

\begin{tabular}{|c|c|c|c|}
\hline $\begin{array}{l}\text { Standard clinical tables in the } \\
\text { OMOP }^{\mathrm{a}} \mathrm{CDM}^{\mathrm{b}}\end{array}$ & Variable of personal health identifier & $\begin{array}{l}\text { Demographic variable of quasi- } \\
\text { identifier }\end{array}$ & Clinical variable of quasi-identifier \\
\hline Person & Month_of_birth and Day_of_birth & $\begin{array}{l}\text { Year_of_birth, Gender_con- } \\
\text { cept_id, Race_concept_id, and } \\
\text { Ethnicity_concept_id }\end{array}$ & $\mathrm{N} / \mathrm{A}^{\mathrm{c}}$ \\
\hline Death & Death_date & N/A & N/A \\
\hline Device_exposure & $\begin{array}{l}\text { Device_exposure_start_date and De- } \\
\text { vice_exposure_end_date }\end{array}$ & N/A & Device_concept_id \\
\hline Drug_exposure & $\begin{array}{l}\text { Drug_exposure_start_date and } \\
\text { Drug_exposure_end_date }\end{array}$ & N/A & Drug_concept_id \\
\hline Location & County & State & N/A \\
\hline Measurement & Measurement_date & N/A & Measurement_concept_id \\
\hline Observation & Observation_date & N/A & Observation_concept_id \\
\hline Procedure_occurrence & Procedure_date & N/A & Procedure_concept_id \\
\hline Visit_occurrence & Visit_start_date and Visit_end_date & N/A & N/A \\
\hline Condition_occurrence & $\begin{array}{l}\text { Condition_start_date and Condi- } \\
\text { tion_end_date }\end{array}$ & N/A & Condition_concept_id \\
\hline Provider & $\mathrm{NPI}^{\mathrm{d}}$ & N/A & N/A \\
\hline Care_site & N/A & N/A & Place_of_service_concept_id \\
\hline
\end{tabular}

${ }^{a}$ OMOP: Observational Medical Outcomes Partnership.

${ }^{\mathrm{b}} \mathrm{CDM}$ : common data model.

${ }^{\mathrm{c}} \mathrm{N} / \mathrm{A}$ : not applicable.

${ }^{\mathrm{d}} \mathrm{NPI}$ : national provider identifier.

\section{Study Design}

We conducted privacy risk experiments of the PHIs and QIs. We generated data sets for each experiment. The workflow for this study is shown in Figure 1. In the privacy risk experiment of the PHIs, 16 limited data sets were generated, with each comprising one of the 16 PHIs merged with five common demographic variables (Year_of_birth, Gender_concept_id, Race_concept_id, Ethnicity_concept_id, and State), as in previous clinical studies [53,54]. For example, Condition_start_date, which is the name of data set 1 of the 16 limited data sets, consists of one PHI (Condition_start_date variable) and five common demographic variables. Another example is the Procedure_date data set consisting of one PHI (Procedure_date variable) and five common demographic variables. Thus, each limited data set consists of six variables.

In the QI privacy risk experiment, we mocked up seven scenarios based on the core tables of the OMOP CDM [16,59-61], which are frequently used in the real world. The seven scenarios are as follows: (1) diagnosis, (2) procedure, (3) drug treatment, (4) lab test, (5) device treatment, (6) death, and (7) medical history (Multimedia Appendix 3). Based on the scenarios, seven limited data sets were generated: 10 PHIs and seven QIs were assigned according to the characteristics of each scenario differently, and five demographic variables and six PHIs were used as common variables (Multimedia Appendix 3). For example, the diagnosis scenario consisted of 14 variables as follows: two PHIs (Condition_start_date and
Condition_end_date) and one QI (Condition_concept_id), which followed the characteristics of the diagnosis scenario, and 11 common variables were merged.

To compare different deidentification levels for the same data set, we applied the safe harbor policy to the 16 limited data sets. For example, when the safe harbor policy was applied to the limited data set, the PHIs were partially or completely masked. The date type (such as start date, end date, and death date) was masked from "YYYY-MM-DD" to "YYYY-**_**." In other words, they used only the "year". The others (such as Month_of_birth, Day_of_birth, NPI, and County) were completely masked. We additionally generated 16 and seven safe harbor data sets for PHIs and QIs, respectively, by applying the safe harbor policy on the limited data sets.

\section{Privacy Risk Evaluation Metrics}

An equivalence class (EC) denotes a group of indistinguishable record forms with common attributes. The common attribute sizes that are included in each group can be represented as the calculated size of the EC [46]. An EC size of one represents the highest possibility of privacy disclosure for a certain patient's information [56]. In contrast, if the size is maximum, it indicates the highest deidentification level of the data set. In previous studies, the minimum cell size was an empirically defined threshold with the calculated EC size [56,57]. The minimum cell size determines the level of deidentification and measures the privacy risk in the data set. The most commonly used minimum cell size in practice is five, and a larger size, such as 
20 , is used for data sets that include highly sensitive patient information [56]. The minimum cell size, calculated by the EC, was compared for both the limited and safe harbor data sets.

The trust differential mechanism represents the privacy risk of a data set with a gap obtained by comparing two different deidentification levels [54]. The gap represents the following two factors: (1) the quantified difference of the deidentification level and (2) the degree of decrease in privacy risk. In other words, when a certain privacy policy applies to the data set that complies with another privacy policy, a gap will occur between the two different privacy policies, which have different deidentification levels. Therefore, the gap indicates that the data set's privacy level with the lower deidentification privacy policy could be protected as the difference that arises when the higher privacy policy is applied.

Through the PHI and QI privacy risk experiments, we measured privacy risk in terms of the following two aspects: (1) measurements based on the number of total records in each data set and (2) measurements based on the identical number of records through random sampling from each data set. In the first aspect, we considered that clinical studies perform analysis with clinical tables according to clinical scenarios [16,59-61]; thus, we measured privacy risk with the number of total records in the data set generated by referring to previous studies $[53,54]$. With the number of total records, we compared the limited and safe harbor data sets based on the total records of each PHI and
QI. Then, we measured with different minimum cell sizes from each PHI and QI experiment. To measure PHI privacy risk, we compared the limited and safe harbor data sets with the maximum EC size and a minimum cell size of one. In the QI privacy risk experiment, we compared the limited and safe harbor data sets with a minimum cell size of 1 to 20 . In the second aspect, we extracted 1000, 10,000, 100,000, and 1 million random samples from each limited and safe harbor data set and iterated them 100 times. With the iterated random samples, we calculated the average of the minimum cell size 1 and then compared the limited and safe harbor data sets for PHIs and QIs.

\section{Results}

\section{Overview}

Overall, when compared with the limited and safe harbor data sets, privacy risk was reduced in both PHIs and QIs according to the trust differential gap. For the trust differential gap of a minimum cell size of one, there are two overall results. In the number of total records, the trust differential gaps of PHIs and QIs averaged $31.448 \%$ and $73.798 \%$, respectively. In the random samples, the trust differential gaps of PHIs and QIs averaged $18.869 \%$ and $6.493 \%$ (1000 samples), $50.730 \%$ and $33.248 \%$ (10,000 samples), $74.013 \%$ and $60.306 \%$ (100,000 samples), and $50.744 \%$ and $71.868 \%$ (1,000,000 samples), respectively (Table 2).

Table 2. The averaged trust differential gap according to total records and random samples.

\begin{tabular}{|c|c|c|}
\hline \multirow[t]{2}{*}{ Number of total records ${ }^{\mathrm{a}}$ and sample $\mathrm{e}^{\mathrm{b}}$} & \multicolumn{2}{|c|}{ Trust differential gap ${ }^{c}$ with a minimum cell size of one ${ }^{d}$} \\
\hline & Personal health identifier (mean percentage) & Quasi-identifier (mean percentage) \\
\hline Number of total records & $31.448 \%$ & $73.798 \%$ \\
\hline \multicolumn{3}{|l|}{ Sample } \\
\hline 1000 & $18.869 \%$ & $6.493 \%$ \\
\hline 10,000 & $50.730 \%$ & $33.248 \%$ \\
\hline 100,000 & $74.013 \%$ & $60.306 \%$ \\
\hline $1,000,000$ & $50.744 \%$ & $71.868 \%$ \\
\hline
\end{tabular}

\footnotetext{
a Number of total records is each personal health identifier's total record. number of total records as the denominator.

\section{Evaluation of the Personal Health Identifier Privacy Risk of the DRN}

${ }^{\mathrm{b}}$ Sample is the number of random samples (ie, 1000, 10,000, 100,000, or 1 million) from the limited and safe harbor data sets.

${ }^{\mathrm{c}}$ Trust differential gap is the difference obtained by comparing two data sets to measure privacy risk.

${ }^{\mathrm{d}}$ Minimum cell size of one is the percentage of unique records. This can be expressed with the number of unique records as the numerator and the

In the number of total record results of the limited data set, the variable with the most included minimum cell size of one was Death_date, which was $98.787 \%(1141 / 1155)$. In addition, the maximum EC size of two for Death_date means that every record consists of only two value types. In Death_date of the safe harbor data set, the minimum cell size of one was $87.359 \%$ (1009/1155), and the maximum EC size was three. Even though the safe harbor policy was applied, privacy was still threatened. In the Death_date trust differential gap, the gap with a minimum cell size of one was $11.428 \%$, and the maximum EC size was one. The maximum EC size of one is the lowest trust differential gap among all the maximum EC size gaps. In the limited data set, the variable with the least minimum cell size of one was Condition_end_date, which was $4.540 \%(146,727 / 3,231,730)$. In Condition_end_date from the safe harbor data set, the minimum cell size of one was $0.003 \%(125 / 3,231,730)$. Even though the safe harbor policy was applied, the records of a minimum cell size of one did not significantly decrease. In the Condition_end_date trust differential gap, the minimum cell size of one was $4.536 \%$, and the maximum EC size was 2348 . This maximum EC size of 2348 was the highest trust differential 
gap among all the maximum EC size gaps. In the trust differential gaps with a minimum cell size of one, the NPI variable had the highest trust differential gap of $71.236 \%$, which was the difference between the limited (71.244\%) and safe harbor $(0.007 \%)$ data sets. For Drug_exposure_start_date and Drug_exposure_end_date, both data sets exhibited the same maximum EC size and a minimum cell size of one.

Day_of_birth consists of the day part of the date of birth and was already deidentified as " 1 " in the SynPUF5PCT data set (eg, "dd" to "1"); thus, every patient had the exact same Day_of_birth value. Because it was the same deidentified method as for the safe harbor policy, the Day_of_birth trust differential gap was zero (Table 3 ). It could be provided as a statistical baseline for five demographic variables without any PHI variables. When the measured result of the Day_of_birth variable $(13.079 \%)$ was compared with that of the Condition_end_date variable, the result of the Condition_end_date variable was lower by 8.539 percentage points (from $13.079 \%$ to $4.540 \%$ ), and when it was compared with that of the Death_date variable, the result of the Death_date variable was higher by 85.708 percentage points (from $13.079 \%$ to $98.787 \%$ ).

Table 3. Comparison of 16 personal health identifier variables and five demographic variables of the SynPUF5PCT with limited and safe harbor data sets in terms of a minimum cell size of one and the maximum size of the equivalence class.

\begin{tabular}{|c|c|c|c|c|c|c|c|c|c|}
\hline \multirow[t]{2}{*}{ Variable $^{\mathrm{a}}$} & \multirow{2}{*}{$\begin{array}{l}\text { Number of } \\
\text { total } \\
\text { records }{ }^{b}\end{array}$} & \multicolumn{3}{|c|}{ Limited data set } & \multicolumn{3}{|c|}{ Safe harbor data set } & \multicolumn{2}{|c|}{ Trust differential gap ${ }^{c}$} \\
\hline & & $\begin{array}{l}\text { Number of } \\
\text { unique } \\
\text { records }\end{array}$ & $\begin{array}{l}\text { Minimum } \\
\text { cell size of } \\
\text { one }^{\mathrm{e}}(\%)\end{array}$ & $\begin{array}{l}\text { Maximum } \\
\text { size of the } \\
\text { equiva- } \\
\text { lence class } \mathrm{f}\end{array}$ & $\begin{array}{l}\text { Number of } \\
\text { unique } \\
\text { records }^{\mathrm{d}}\end{array}$ & $\begin{array}{l}\text { Minimum } \\
\text { cell size of } \\
\text { one }^{\mathrm{e}}(\%)\end{array}$ & $\begin{array}{l}\text { Maximum } \\
\text { size of the } \\
\text { equiva- } \\
\text { lence class }\end{array}$ & $\begin{array}{l}\text { Minimum } \\
\text { cell size } \\
\text { of one } \\
(\%)\end{array}$ & $\begin{array}{l}\text { Maximum } \\
\text { size of the } \\
\text { equiva- } \\
\text { lence class }\end{array}$ \\
\hline Visit_start_date & $1,218,881$ & 771,684 & 63.310 & 10 & 581 & 0.047 & 888 & 62.952 & 878 \\
\hline Visit_end_date & $1,218,881$ & 771,891 & 63.327 & 10 & 581 & 0.0395 & 889 & 62.960 & 879 \\
\hline Death_date & 1155 & 1141 & 98.787 & 2 & 1009 & 87.359 & 3 & 11.428 & 1 \\
\hline Condition_start_date & $3,231,730$ & 146,828 & 4.543 & 45 & 137 & 0.004 & 2391 & 4.538 & 2346 \\
\hline Condition_end_date & $3,231,730$ & 146,727 & 4.540 & 45 & 125 & 0.003 & 2393 & 4.536 & 2348 \\
\hline Procedure_date & $3,024,452$ & 257,161 & 8.502 & 64 & 201 & 0.006 & 2180 & 8.495 & 2116 \\
\hline Measurement_date & 741,161 & 168,180 & 22.691 & 43 & 595 & 0.080 & 575 & 22.610 & 532 \\
\hline Observation_date & 420,986 & 182,497 & 43.349 & 28 & 983 & 0.233 & 335 & 43.115 & 307 \\
\hline $\begin{array}{l}\text { Device_expo- } \\
\text { sure_start_date }\end{array}$ & 47,655 & 13,232 & 27.766 & 40 & 3190 & 6.693 & 218 & 21.073 & 178 \\
\hline $\begin{array}{l}\text { Device_expo- } \\
\text { sure_end_date }\end{array}$ & 47,655 & 13,219 & 27.739 & 40 & 3191 & 6.696 & 187 & 21.043 & 147 \\
\hline $\begin{array}{l}\text { Drug_expo- } \\
\text { sure_start_date }\end{array}$ & 158,316 & 55,042 & 34.767 & 45 & 2845 & 1.797 & 409 & 32.970 & 364 \\
\hline $\begin{array}{l}\text { Drug_expo- } \\
\text { sure_end_date }\end{array}$ & 158,316 & 55,042 & 34.767 & 45 & 2845 & 1.797 & 409 & 32.970 & 364 \\
\hline Month_of_birth & 25,200 & 14,508 & 57.571 & 8 & 3296 & 13.079 & 49 & 44.492 & 41 \\
\hline Day_of_birth & 25,200 & 3296 & 13.079 & 49 & 3296 & 13.079 & 49 & 0 & 0 \\
\hline $\mathrm{NPI}^{\mathrm{g}}$ & $1,215,317$ & 865,840 & 71.244 & 70 & 91 & 0.007 & 2247 & 71.236 & 2177 \\
\hline County & 25,200 & 18,103 & 71.837 & 12 & 3296 & 13.079 & 49 & 58.757 & 37 \\
\hline Average & $\mathrm{N} / \mathrm{A}^{\mathrm{h}}$ & N/A & 40.488 & 34.75 & N/A & 8.999 & 829.437 & 31.448 & 771.937 \\
\hline
\end{tabular}

${ }^{\mathrm{a}}$ Variable refers to the variable targeted from the Observational Medical Outcomes Partnership common data model as the personal health identifier.

${ }^{b}$ Number of total records is each personal health identifier's total record.

${ }^{\mathrm{c}}$ Trust differential gap is the difference obtained by comparing two data sets to measure privacy risk.

${ }^{\mathrm{d}}$ Number of unique records is the number of records with a common attribute size of one within the total record.

${ }^{\mathrm{e}}$ Minimum cell size of one is the percentage of unique records. This can be expressed with the number of unique records as the numerator and the number of total records as the denominator.

${ }^{\mathrm{f}}$ Maximum size of the equivalence class is the largest size of the indistinguishable common attributes.

${ }^{\mathrm{g}}$ NPI: national provider identifier.

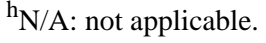


In randomly sampled PHIs, privacy risk reduction was different depending on the number of samples (Table 4 and Multimedia Appendix 4). The variables with a highly ranked trust differential gap were Device_exposure_start_date (1000 samples) $(33.730 \% ; 87.705 \%$ and $53.975 \%$ in the limited and safe harbor data sets, respectively), NPI (10,000 samples) (83.852\%; $98.945 \%$ and $15.094 \%$ in the limited and safe harbor data sets, respectively), Visit_start_date (100,000 samples) $(92.566 \% ; 95.583 \%$ and $3.016 \%$ in the limited and safe harbor data sets, respectively), and NPI (1,000,000 samples) $(73.588 \%$; $73.599 \%$ and $0.011 \%$ in the limited and safe harbor data sets, respectively).

Overall, for 1000 random samples, both data sets consisted primarily of the minimum cell size of one. In the limited data set, the variables with the most and fewest included minimum cell size of one records were Visit_end_date (99.978\%) and Day_of_birth (73.754\%), respectively. In the safe harbor data set, the variables with the most and fewest included minimum cell size of one records were Death_date $(89.044 \%)$ and NPI $(67.377 \%)$, respectively (Table 4). For Visit_end_date in the limited data set with the most included minimum cell size of one records, after applying the safe harbor policy, the minimum cell size of one records of the Visit_end_date variable decreased to $86.171 \%$ (861.710/1000). Even though the safe harbor policy was applied, the minimum cell size of one records did not decrease significantly. Death_date, with the most included minimum cell size of one records in the safe harbor data set, had a trust differential gap of $9.862 \%$ (98.906\% and $89.044 \%$ in the limited and safe harbor data sets, respectively). The privacy risk did not decrease significantly after applying the safe harbor policy. In the trust differential gap, the variable with the highest gap was Device_exposure_start_date $(33.730 \%$; $87.705 \%$ and $53.975 \%$ in the limited and safe harbor data sets, respectively). When the safe harbor policy was applied, the Death_date privacy risk could be significantly reduced. In the number of total records of the limited and safe harbor data sets, with a minimum cell size of one, the most privacy-threatening variables were Death_date $(98.787 \%)$ and Death_date (87.359\%), respectively. However, in the random sample of 1000 , it was Visit_end_date $(99.978 \%)$ and Death_date $(89.044 \%)$, respectively. Therefore, we verified that privacy-threatening variables could differ depending on the number of records. Detailed random sampled results are displayed in Multimedia Appendix 4. 
Table 4. Comparison of records with a minimum cell size of one between the limited and safe harbor data sets from 16 personal health identifier data sets.

\begin{tabular}{|c|c|c|c|c|c|}
\hline \multirow[t]{3}{*}{ Sample $^{\mathrm{a}}$ and variable ${ }^{\mathrm{b}}$} & \multirow{2}{*}{\multicolumn{2}{|c|}{$\begin{array}{l}\text { Limited data set } \\
\text { Number of minimum cell sizes of one }{ }^{d}\end{array}$}} & \multirow{2}{*}{\multicolumn{2}{|c|}{$\begin{array}{l}\text { Safe harbor data set } \\
\text { Number of minimum cell sizes of one }{ }^{d}\end{array}$}} & \multirow{3}{*}{$\begin{array}{l}\text { Trust differential } \\
\operatorname{gap}^{\mathrm{c}}(\%)\end{array}$} \\
\hline & & & & & \\
\hline & $\operatorname{Mean}{ }^{\mathrm{e}}\left(\mathrm{SD}^{\mathrm{f}}\right)$ & Percentage $^{\mathrm{g}}(\%)$ & $\operatorname{Mean}{ }^{e}\left(\operatorname{SD}^{f}\right)$ & Percentage $^{\mathrm{g}}(\%)$ & \\
\hline \multicolumn{6}{|l|}{1000 samples } \\
\hline Visit_start_date & $999.26(1.125)$ & 99.926 & $859.68(16.229)$ & 85.968 & 13.958 \\
\hline Visit_end_date & $999.78(0.629)$ & 99.978 & $861.71(15.086)$ & 86.171 & 13.807 \\
\hline Death_date & $989.06(2.155)$ & 98.906 & $890.44(7.478)$ & 89.044 & 9.862 \\
\hline Condition_start_date & $998.44(1.766)$ & 99.844 & $857.59(15.178)$ & 85.759 & 14.085 \\
\hline Condition_end_date & $998.12(2.006)$ & 99.812 & $858.7(16.45)$ & 85.87 & 13.942 \\
\hline Procedure_date & $998.24(1.804)$ & 99.824 & $858.61(16.504)$ & 85.861 & 13.963 \\
\hline Measurement_date & $995.14(2.971)$ & 99.514 & $855.11(15.321)$ & 85.511 & 14.003 \\
\hline Observation_date & $997.54(2.162)$ & 99.754 & $854.79(14.238)$ & 85.479 & 14.275 \\
\hline Device_exposure_start_date & 877.05 (13.107) & 87.705 & $539.75(16.877)$ & 53.975 & 33.73 \\
\hline Device_exposure_end_date & $875.34(16.05)$ & 87.534 & $539.68(20.112)$ & 53.968 & 33.566 \\
\hline Drug_exposure_start_date & $956.34(8.669)$ & 95.634 & 720.7 (17.729) & 72.07 & 23.564 \\
\hline Drug_exposure_end_date & $956.34(8.669)$ & 95.634 & $720.7(17.729)$ & 72.07 & 23.564 \\
\hline Month_of_birth & $971.47(7.612)$ & 97.147 & $738.4(17.707)$ & 73.84 & 23.307 \\
\hline Day_of_birth & $737.54(17.774)$ & 73.754 & $737.54(17.774)$ & 73.754 & 0 \\
\hline $\mathrm{NPI}^{\mathrm{h}}$ & $998.8(1.775)$ & 99.88 & $673.77(19.212)$ & 67.377 & 32.503 \\
\hline County & $979.69(6.59)$ & 97.969 & $738.46(16.856)$ & 73.846 & 24.123 \\
\hline Average & $\mathrm{N} / \mathrm{A}^{\mathrm{i}}$ & N/A & N/A & N/A & 18.869 \\
\hline
\end{tabular}

${ }^{\mathrm{a}}$ Sample is the number of random samples (ie, 1000, 10,000, 100,000, or 1 million) from the limited and safe harbor data sets.

${ }^{b}$ Variable is the variable targeted from the Observational Medical Outcomes Partnership common data model as the personal health identifier.

${ }^{\mathrm{c}}$ Trust differential gap is the difference obtained by comparing two data sets to measure privacy risk.

${ }^{\mathrm{d}}$ Number of minimum cell sizes of one is the number of records with a unique record among the total records.

${ }^{\mathrm{e}}$ Mean is the average of the quantity with a minimum cell size of one obtained by iterating the random sampling of each variable 100 times.

${ }^{\mathrm{f}} \mathrm{SD}$ is the standard deviation of the quantity with a minimum cell size of one obtained by iterating random sampling of each variable 100 times.

${ }^{\text {g }}$ Percentage is the percentage of the quantity with a minimum cell size of one. The numerator is the mean of the minimum cell size of one, which was obtained from 100 iterations, and the denominator was the number of random samples.

$\mathrm{h}_{\mathrm{NPI}}$ : national provider identifier.

${ }^{\mathrm{i}} \mathrm{N} / \mathrm{A}$ : not applicable.

\section{Evaluation of the Quasi-Identifier Privacy Risk of the DRN}

In the results for the number of total records, the privacy risk of the QI with a minimum cell size of 1 to 20 was measured in the limited and safe harbor data sets. As shown in Figure 2, for the minimum cell size of one, the minimum and maximum percentages in the seven scenarios were $71 \%$ and $99 \%$, respectively, in the limited data set (Figure $2 \mathrm{~A}$ ) and $0.7 \%$ and $41 \%$, respectively, in the safe harbor data set (Figure 2B). The QI privacy risk was represented with a minimum cell size of one to five (Multimedia Appendix 5 and Table 5). For the minimum cell size of one in the limited data set, the Diagnosis (71.465\%) and Procedure (76.123\%) scenarios showed lower privacy risks than the other five scenarios (Drug treatment [95.475\%], Lab test [93.012\%], Medical history [92.353\%], Death [99.997\%], and Device treatment [97.647\%]). For the Death scenario, the limited data set records were concentrated in the minimum cell size of one to two. The average gaps between the limited and safe harbor data sets, with the minimum cell size of one to five decreased from $73.798 \%$ to $54.548 \%$. For the gaps of the minimum cell size of one, the Diagnosis scenario showed the smallest gap (28.869\%), whereas the Death scenario showed the largest gap (99.212\%). 
Figure 2. Percentage of records measuring the quasi-identifier privacy risk with a minimum cell size of 1-20 for the (A) limited and (B) safe harbor data sets. The flattened lines are expanded (inner graph).

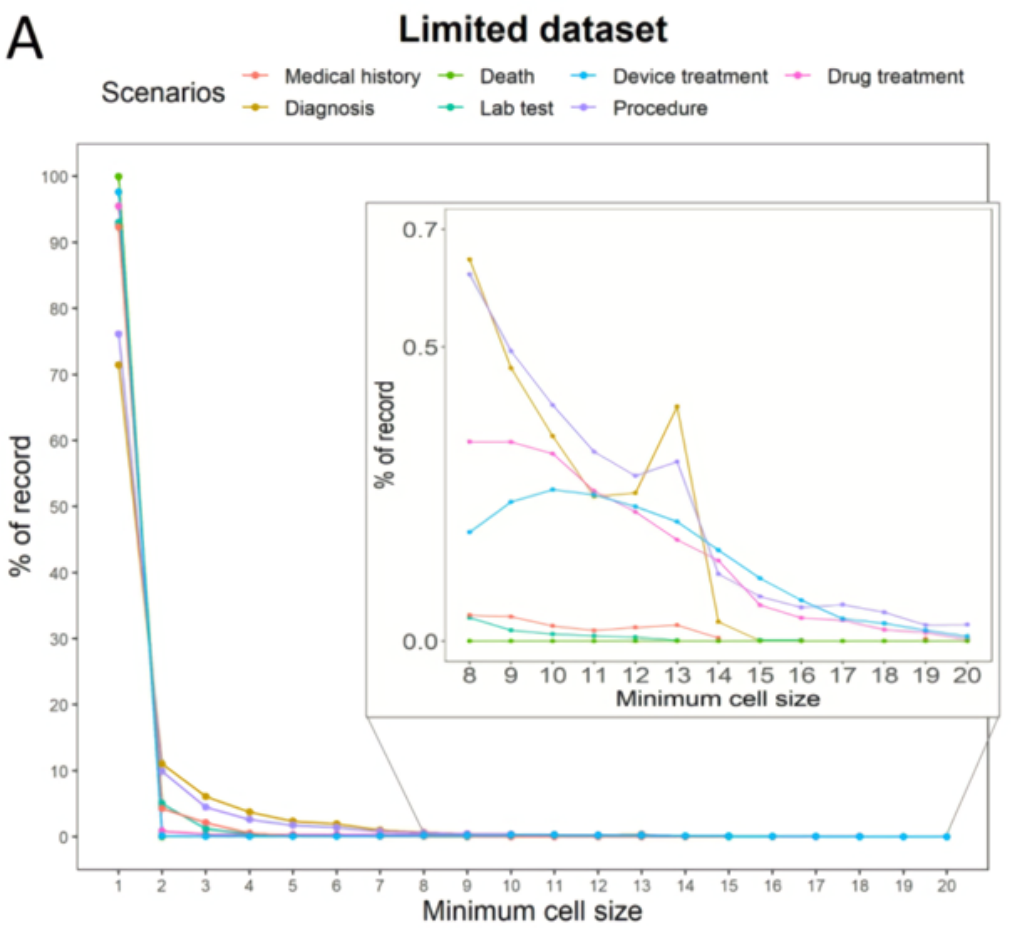

B

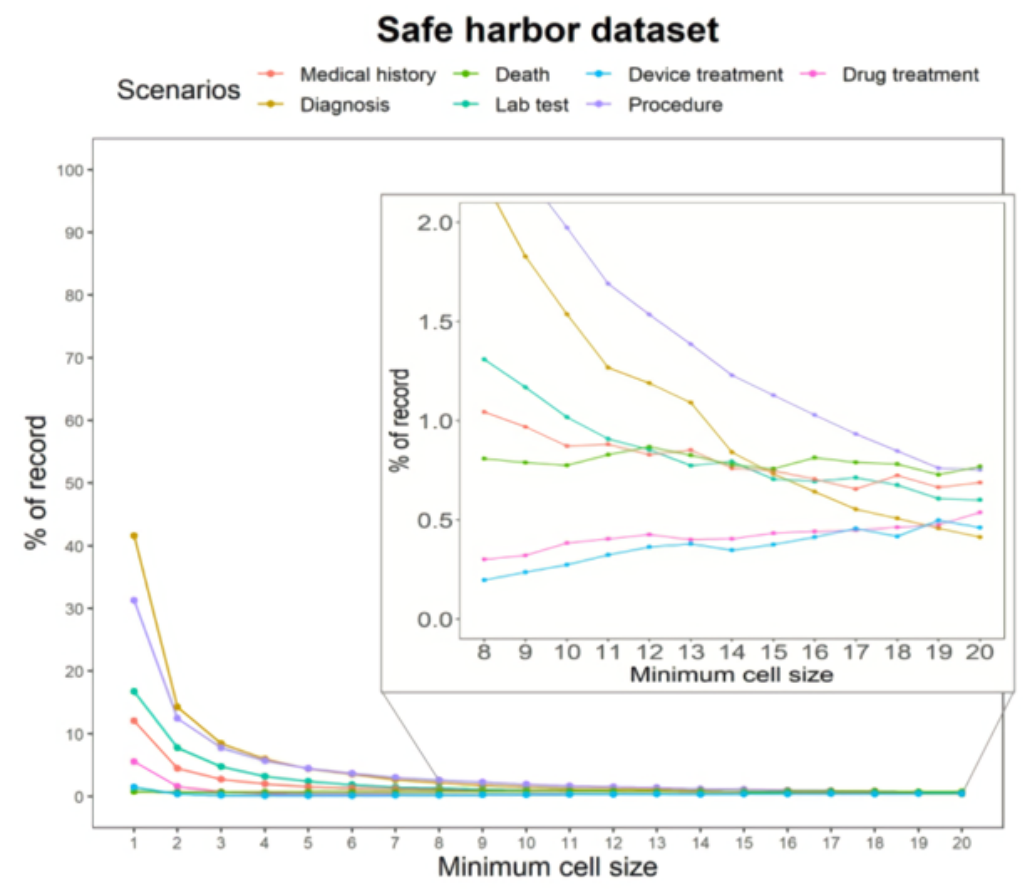


Table 5. Percentage of records measuring quasi-identifier privacy risk with gaps between the limited and safe harbor data sets with a minimum cell size of one, two, and five.

\begin{tabular}{|c|c|c|c|c|c|c|c|c|c|c|}
\hline \multirow[t]{2}{*}{ Scenarios } & \multirow[t]{2}{*}{$\begin{array}{l}\text { Number of } \\
\text { total } \\
\text { records }\end{array}$} & \multicolumn{3}{|c|}{$\begin{array}{l}\text { Limited data set } \\
\text { Minimum cell size of one, two, and five, } \\
\text { percentage }^{c}\left(\text { record }^{d}\right)\end{array}$} & \multicolumn{3}{|c|}{$\begin{array}{l}\text { Safe harbor data set } \\
\text { Minimum cell size of one, two, and five, } \\
\left.\text { percentage }^{c} \text { (record }^{d}\right)\end{array}$} & \multicolumn{3}{|c|}{$\begin{array}{l}\text { Trust differential gap }{ }^{b} \\
\text { Minimum cell size of one, } \\
\text { two, and five, percentage }^{c}\end{array}$} \\
\hline & & 1 & 2 & 5 & 1 & 2 & 5 & 1 & 2 & 5 \\
\hline Diagnosis & $3,369,468$ & $\begin{array}{l}71.465 \\
(2,407,996)\end{array}$ & $\begin{array}{l}11.049 \\
(186,162)\end{array}$ & $\begin{array}{l}2.333 \\
(15,726)\end{array}$ & $\begin{array}{l}41.595 \\
(1,401,556)\end{array}$ & $\begin{array}{l}14.248 \\
(240,043)\end{array}$ & $\begin{array}{l}4.412 \\
(29,737)\end{array}$ & 29.869 & 35.361 & 19.986 \\
\hline Procedure & $3,105,665$ & $\begin{array}{l}76.123 \\
(2,364,135)\end{array}$ & $\begin{array}{l}9.902 \\
(153,767)\end{array}$ & $\begin{array}{l}1.731 \\
(10,752)\end{array}$ & $\begin{array}{l}31.251 \\
(970,568)\end{array}$ & $\begin{array}{l}12.472 \\
(193,672)\end{array}$ & $\begin{array}{l}4.460 \\
(27,708)\end{array}$ & 44.871 & 42.301 & 33.173 \\
\hline Drug treatment & $1,300,649$ & $\begin{array}{l}95.475 \\
(1,241,796)\end{array}$ & $\begin{array}{l}0.895 \\
(5826)\end{array}$ & $0.306(796)$ & $5.558(72,292)$ & $\begin{array}{l}1.625 \\
(10,569)\end{array}$ & $\begin{array}{l}0.356 \\
(927)\end{array}$ & 89.917 & 89.187 & 88.611 \\
\hline Lab test & $1,622,884$ & $\begin{array}{l}93.012 \\
(1,509,486)\end{array}$ & $\begin{array}{l}5.043 \\
(40,923)\end{array}$ & $0.138(448)$ & $\begin{array}{l}16.749 \\
(271,819)\end{array}$ & $\begin{array}{l}7.748 \\
(62,875)\end{array}$ & $\begin{array}{l}2.385 \\
(7744)\end{array}$ & 76.263 & 73.558 & 64.958 \\
\hline Medical history & $1,348,569$ & $\begin{array}{l}92.353 \\
(1,245,455)\end{array}$ & $\begin{array}{l}4.286 \\
(28,900)\end{array}$ & $0.224(606)$ & $\begin{array}{l}12.079 \\
(162,898)\end{array}$ & $\begin{array}{l}4.466 \\
(30,115)\end{array}$ & $\begin{array}{l}1.550 \\
(4183)\end{array}$ & 80.274 & 80.094 & 76.759 \\
\hline Death & $1,218,881$ & $\begin{array}{l}99.997 \\
(1,218,845)\end{array}$ & $0.003(18)$ & $0(0)$ & 0.784 (9557) & $\begin{array}{l}0.686 \\
(4185)\end{array}$ & $\begin{array}{l}0.719 \\
(1755)\end{array}$ & 99.212 & 98.529 & 0 \\
\hline Device treatment & $1,247,726$ & $\begin{array}{l}97.647 \\
(1,218,368)\end{array}$ & $0.152(954)$ & $0.059(149)$ & $1.464(18,271)$ & $\begin{array}{l}0.380 \\
(2372)\end{array}$ & $\begin{array}{l}0.139 \\
(348)\end{array}$ & 96.182 & 95.955 & 95.625 \\
\hline Average & $\mathrm{N} / \mathrm{A}^{\mathrm{e}}$ & N/A & N/A & N/A & N/A & N/A & N/A & 73.798 & 73.569 & 54.458 \\
\hline
\end{tabular}

${ }^{a}$ Number of total records denotes each total record of the scenarios.

${ }^{\mathrm{b}}$ Trust differential gap indicates the differences obtained by comparing two data sets to measure privacy risk.

${ }^{\mathrm{c}}$ Minimum cell size of one, two, and five represents the percentage of records that have a common attribute size of one, two, and five, respectively. This percentage is presented as the records of minimum cell size of one, two, and five as the numerator and the total number of records as the denominator.

${ }^{\mathrm{d}}$ Record is the number of records with a common attribute size of one, two, and five within the total records.

${ }^{\mathrm{e}} \mathrm{N} / \mathrm{A}$ : not applicable.

In the random samples with a minimum cell size of one, (1) the average percentage of the limited data set decreased from $99.986 \%$ to $99.327 \%$, (2) the average percentage of the safe harbor data set decreased from $93.493 \%$ to $21.460 \%$, and (3) the average trust differential gap increased from $6.493 \%$ to $71.868 \%$ (Table 6). In the limited data set with 1000 to 1 million random samples, the scenario with the most included records of a minimum cell size of one was the Death scenario (1000 to 100,000 random samples had $99.999 \%$ and 1 million had $99.998 \%$ ). In the safe harbor data set with 1000 to 1 million random samples, the scenario with the most included records of a minimum cell size of one was the Diagnosis scenario (1000 random samples had $99.858 \%, 10,000$ had $98.685 \%, 100,000$ had $89.758 \%$, and 1 million had $60.361 \%$ ). In the order of the four random samples, the scenarios with the highest trust differential gap were Device_treatment (1000 random samples: $12.980 \%, 99.980 \%$ and $87.000 \%$ in the limited and safe harbor data sets, respectively; 10,000 random samples: $60.118 \%$,

$99.831 \%$ and $39.713 \%$ in the limited and safe harbor data sets, respectively; 100,000 random samples: $93.598 \%, 98.805 \%$ and $5.207 \%$ in the limited and safe harbor data sets, respectively) and Death (1 million random samples: $99.063 \%, 99.998 \%$ and $0.934 \%$ in the limited and safe harbor data sets, respectively). When the safe harbor policy was applied, privacy risks were significantly reduced. In the number of total records, the most privacy-threatening scenarios were Death (99.997\%) and Diagnosis $(41.595 \%)$ in the limited and safe harbor data sets, respectively, with a minimum cell size of one. In the random samples with a minimum cell size of one in the limited data set, the most privacy-threatening scenario was Death, which had privacy risks of $99.999 \%$ (1000 to 100,000 random samples) and $99.998 \%$ (1 million random samples). In the safe harbor data set, Diagnosis had privacy risks of $99.858 \%$ (1000 random samples), $98.685 \%$ (10,000 random samples), 89.758\% (100,000 random samples), and $60.361 \%$ (1 million random samples). 
Table 6. Comparison of records with a minimum cell size of one between the limited and safe harbor data sets from seven scenarios.

\begin{tabular}{|c|c|c|c|c|c|}
\hline \multirow{3}{*}{ Sample $^{\mathrm{a}}$ and scenario ${ }^{\mathrm{b}}$} & \multirow{2}{*}{\multicolumn{2}{|c|}{$\begin{array}{l}\text { Limited data set } \\
\text { Number of minimum cell sizes of one }{ }^{d}\end{array}$}} & \multirow{2}{*}{\multicolumn{2}{|c|}{$\begin{array}{l}\text { Safe harbor data set } \\
\text { Number of minimum cell sizes of one }{ }^{\mathrm{d}}\end{array}$}} & \multirow{3}{*}{$\begin{array}{l}\text { Trust differential } \\
\operatorname{gap}^{\mathrm{c}}(\%)\end{array}$} \\
\hline & & & & & \\
\hline & $\operatorname{Mean}^{\mathrm{e}}\left(\mathrm{SD}^{\mathrm{f}}\right)$ & Percentage $^{\mathrm{g}}(\%)$ & $\operatorname{Mean}{ }^{\mathrm{e}}\left(\mathrm{SD}^{\mathrm{f}}\right)$ & Percentage $^{\mathrm{g}}(\%)$ & \\
\hline \multicolumn{6}{|l|}{1000} \\
\hline Diagnosis & 999.800 & 99.980 & 998.580 & 99.858 & 0.122 \\
\hline Procedure & 999.760 & 99.976 & 997.400 & 99.740 & 0.236 \\
\hline Drug_treatment & 999.860 & 99.986 & 889.470 & 88.947 & 11.039 \\
\hline Lab_test & 999.900 & 99.990 & 956.910 & 95.691 & 4.299 \\
\hline Medical_history & 999.960 & 99.996 & 932.320 & 93.232 & 6.764 \\
\hline Death & 999.990 & 99.999 & 899.830 & 89.983 & 10.016 \\
\hline Device_treatment & 999.800 & 99.980 & 870.000 & 87.000 & 12.980 \\
\hline Average & $\mathrm{N} / \mathrm{A}^{\mathrm{h}}$ & 99.986 & N/A & 93.493 & 6.493 \\
\hline \multicolumn{6}{|l|}{10,000} \\
\hline Diagnosis & 9975.850 & 99.759 & 9868.540 & 98.685 & 1.073 \\
\hline Procedure & 9974.680 & 99.747 & 9743.830 & 97.438 & 2.309 \\
\hline Drug_treatment & 9980.620 & 99.806 & 4642.820 & 46.428 & 53.378 \\
\hline Lab_test & 9993.920 & 99.939 & 7320.070 & 73.201 & 26.739 \\
\hline Medical_history & 9989.730 & 99.897 & 6226.700 & 62.267 & 37.630 \\
\hline Death & 9999.980 & 99.9990 & 4851.230 & 48.512 & 51.487 \\
\hline Device_treatment & 9983.140 & 99.831 & 3971.310 & 39.713 & 60.118 \\
\hline Average & N/A & 99.854 & N/A & 66.606 & 33.248 \\
\hline \multicolumn{6}{|l|}{100,000} \\
\hline Diagnosis & $97,724.930$ & 97.725 & $89,757.540$ & 89.758 & 7.967 \\
\hline Procedure & $97,742.680$ & 97.743 & $82,093.250$ & 82.093 & 15.649 \\
\hline Drug_treatment & $98,419.410$ & 98.419 & $12,062.980$ & 12.063 & 86.356 \\
\hline Lab_test & $99,375.690$ & 99.376 & $42,164.130$ & 42.164 & 57.212 \\
\hline Medical_history & $99,022.020$ & 99.022 & $28,552.750$ & 28.553 & 70.469 \\
\hline Death & $99,999.640$ & 99.999 & 9106.630 & 9.107 & 90.892 \\
\hline Device_treatment & $98,804.960$ & 98.805 & 5206.990 & 5.207 & 93.598 \\
\hline Average & N/A & 98.727 & N/A & 38.420 & 60.306 \\
\hline \multicolumn{6}{|l|}{$1,000,000$} \\
\hline Diagnosis & $846,819.090$ & 84.682 & $603,607.950$ & 60.361 & 24.321 \\
\hline Procedure & $864,575.710$ & 86.458 & $472,502.940$ & 47.250 & 39.207 \\
\hline Drug_treatment & $957,078.730$ & 95.708 & $59,825.330$ & 5.983 & 89.725 \\
\hline Lab_test & $951,528.090$ & 95.153 & $206,809.130$ & 20.681 & 74.472 \\
\hline Medical_history & $936,158.630$ & 93.616 & $134,617.450$ & 13.462 & 80.154 \\
\hline Death & $999,975.900$ & 99.998 & 9344.160 & 0.934 & 99.063 \\
\hline Device_treatment & $976,802.140$ & 97.680 & $15,496.020$ & 1.550 & 96.131 \\
\hline Average & N/A & 93.327 & N/A & 21.460 & 71.868 \\
\hline
\end{tabular}

${ }^{\text {a }}$ Sample is the number of random samples (ie, 1000, 10,000, 100,000, or 1 million) from the limited and safe harbor data sets.

${ }^{\mathrm{b}}$ Scenario is the variable targeted from the Observational Medical Outcomes Partnership common data model as the personal health identifier.

${ }^{\mathrm{c}}$ Trust differential gap is the difference obtained by comparing two data sets to measure privacy risk.

${ }^{d}$ Number of minimum cell sizes of one is the number of records with a unique record among the total records. 
${ }^{\mathrm{e}}$ Mean is the average of the quantity with a minimum cell size of one obtained by iterating the random sampling of each variable 100 times. ${ }^{\mathrm{f}} \mathrm{SD}$ is the standard deviation of the quantity with a minimum cell size of one obtained by iterating random sampling of each variable 100 times.

g Percent is the percentage of the quantity with a minimum cell size of one. The numerator is the mean of the minimum cell size of one, which was obtained from 100 iterations, and the denominator was the number of random samples.

${ }^{\mathrm{h}}$ N/A: not applicable.

\section{Discussion}

\section{Principal Findings}

In this study, we quantified the DRN privacy risk focusing on PHIs and QIs using 18 HIPAA identifiers and the findings of previous studies [34-43]. To measure the DRN privacy risk, we compared the limited data set, consisting of PHIs and QIs from the SynPUF5PCT data set, with the safe harbor data set generated by applying the safe harbor policy on the limited data set. More specifically, privacy risk was measured with the gap obtained between the two data sets, based on the trust differential, applying the threshold of the minimum cell size with the calculated size by the EC. We verified that the PHIs and QIs increased the DRN privacy risk. However, the privacy risk decreased overall when the safe harbor policy was applied to the DRN. To the best of our knowledge, this is the first study to verify that PHIs and QIs may threaten patient privacy within DRNs.

Prior studies have shown that patient privacy is threatened by PHIs and QIs within clinical databases [53,54]. The DRN of this study may have the same privacy risk as those in previous studies because the DRN at a single site follows a conventional database, although it does not share data [34-41]. Therefore, the privacy risk in a DRN should be quantified and objectively measured for three important reasons. First, because existing patient information in a CDM affects the privacy risk, the DRN privacy risk can be mitigated by providing objectively measured PHI and QI privacy risks [62]. Second, researchers can understand the mechanism of privacy risk change with the objective differences measured by comparing two different deidentification levels of data sets [63]. Finally, an objective measurement of privacy risk will contribute to the design of more secure privacy protection methods suitable for a DRN.

\section{Consideration for Measuring Privacy Risk From Variable Characteristics}

The PHI results, which measure the privacy risk, were verified in two different deidentification levels and indicated a much greater privacy risk reduction in the safe harbor data set than in the limited data set. In addition, we found that privacy risks differ depending on PHI characteristics. The privacy risk of the Visit_start_date variable, which occurs multiple times per patient, was significantly reduced after applying the safe harbor policy. However, the Death_date variable, which occurs only once per patient, still had many remaining unique records after the safe harbor policy was applied. The State variable, which is one of the demographic variables in the data set of the Death_date variable, still had unique values because it had not been deidentified by the safe harbor policy. Although the NPI variable had the highest reduction rate of privacy risk after applying the safe harbor policy, we found that it could not be used as data because it was completely masked. For the
Day_of_birth as a statistical baseline, we compared the Day_of_birth with other PHI variables and could interpret a privacy risk according to the characteristics of the variable as follows. First, because each patient had multiple points for the Condition_end_date value in the SynPUF5PCT, there were fewer unique records relatively. Thus, the privacy risk of Condition_end_date was lower than that of Day_of_birth. Second, because every patient had only one point for the Death_date value, most of them had unique records. Thus, the privacy risk of Death_date was higher than that of Day_of_birth.

In the results of QI, when the limited data set had a minimum cell size of one, the privacy risk differed based on the characteristics of the scenario. In our study, we found that the QI privacy risks of the Drug treatment, Lab test, Medical history, Death, and Device treatment scenarios decreased on average 1.3 times more than those of the Diagnosis and Procedure scenarios, with a minimum cell size of one. The reason for the relatively low reduction in privacy risk under the Diagnosis and Procedure scenarios is that clinical order codes, such as Condition_concept_id and Procedure_concept_id, which used QIs, were prescribed three times on average with the same code.

The privacy risk could differ depending on the characteristics of variables, and the "balls and bins problem" theoretical basis supports our research [64]. As the number of bins increases, it could frequently take only one ball to fill than fewer bins. Similarly, the Visit_end_date variable, with 1096 distinct values ("bins"), consisted of more unique records ("only one ball") than the Month_of_birth with 12 distinct values. Consequently, a privacy protection approach must be customized or optimized by considering the characteristics of each variable.

\section{Consideration for Measuring Privacy Risk From Record Extraction}

Through the random samples, we found the following two facts: (1) Depending on the number of records, the privacy-threatening variable or scenario could differ and (2) The influence of safe harbor policy could differ depending on the number of records, because the number of unique records, which are included with PHI data sets or QI scenarios, differs according to each random sampling. Therefore, to measure the true privacy risk of PHIs and QIs, it is necessary to compare the same records through random sampling.

A minimum cell size of five, which has been a commonly used threshold in previous studies [56], may be difficult to apply as a threshold for measuring the DRN privacy risk. In the QI privacy risk experiment, the Death scenario of the limited data set was not appropriate for a minimum cell size of five because the records were concentrated in a minimum cell size of one to two. Therefore, our results reflect the fact that a minimum cell size of five may not be suitable for the current DRN. However, it should be recognized that the captured features may differ according to the data set used. Therefore, further research is 
required using various real-world data sets to find an appropriate minimum cell size that can contribute to the measurement of the DRN privacy risk.

\section{Limitations}

This study has some limitations. First, this study used a public data set (SynPUF5PCT), which does not handle all PHIs or QIs existing in a DRN. Therefore, we could not consider the CDM of real-world data sets generated by each institution. However, the results of this study are reliable because the SynPUF5PCT data set is an officially published data set by the OHDSI [50]. Second, when measuring the QI privacy risk, some QIs were considered based on scenarios and not based on all variables. Thus, we did not handle the privacy risk considering the combination of all QIs. However, the CDM does not use all variables because the research is based on clinical questions [59]. In addition, we focused on the frequently used scenarios. Third, we did not consider some PHIs and QIs within free text from Note and Note_nlp tables [48], because in our research methodology, PHIs and QIs are detected in the structure of OMOP CDM based on 18 HIPAA identifiers and not in the free text. However, previous studies have indicated that free text includes not only PHIs and QIs but also direct identifiers
$[65,66]$. Therefore, further research needs to include a free text data set. Fourth, we did not consider privacy risk depending on the timespan. Because the SynPUF5PCT data set used in this study contained only 3-year records (2008-2010) and the Day_of_birth variable had already been deidentified as " 1 ," we could not measure privacy risk according to an extended (such as 20-year records) or a narrowed (such as single-week records) timespan. A future study should consider timespan-related privacy.

\section{Conclusions}

In this study, we validated and quantified the privacy risks of PHIs and QIs in the DRN. We objectively measured the privacy risk reduction with the gaps obtained by comparing a safe harbor policy with the DRN. In addition, we measured the true privacy risk of PHIs and QIs by random sampling to adjust for the influence of the number of records. Therefore, it is necessary to reinforce a level of privacy protection for each institution because the DRN involves big data research based on multi-institution collaboration. Our study findings can help in constructing an advanced DRN environment that protects these privacy risks as a quality measurement index.

\section{Acknowledgments}

This study was supported by the Foundational Technology Development Program (NRF2019M3E5D406468221) of the Ministry of Science and ICT, Republic of Korea, and a grant from the Korea Health Technology R\&D Project through the Korea Health Industry Development Institute (KHIDI), funded by the Ministry of Health \& Welfare, Republic of Korea (grant number: HI19C0189).

\section{Conflicts of Interest}

None declared.

\section{Multimedia Appendix 1}

Forty-five personal health identifiers and 17 quasi-identifiers in the structure of the Observational Medical Outcome Partnership common data model.

[DOCX File, 18 KB-Multimedia Appendix 1]

\section{Multimedia Appendix 2}

Detailed information of 16 personal health identifier variables and 12 quasi-identifier scenarios. [DOCX File, 37 KB-Multimedia Appendix 2]

\section{Multimedia Appendix 3}

Seven scenarios with personal health identifiers and quasi-identifiers in the Observational Medical Outcome Partnership common data model, based on not null values in the Synthetic Public Use File 5 Percent data set.

[DOCX File, 17 KB-Multimedia Appendix 3]

\section{Multimedia Appendix 4}

Random sampling and 100 iterations were conducted to compare records with a minimum cell size of one between the limited and safe harbor data sets from 16 personal health identifier data sets.

[DOCX File, 27 KB-Multimedia Appendix 4]

\section{Multimedia Appendix 5}

Percentage of records measuring quasi-identifier privacy risk with gaps between the limited and safe harbor data sets with a minimum cell size of one to five. 
[DOCX File, 15 KB-Multimedia Appendix 5]

\section{References}

1. NIH Collaboratory Distributed Research Network (DRN). Rethinking Clinical Trials. URL: https://rethinkingclinicaltrials. org/nih-collaboratory-drn/ [accessed 2020-08-01]

2. Passerat-Palmbach J, Farnan T, McCoy M, Harris JD, Manion ST, Flannery HL, et al. Blockchain-orchestrated machine learning for privacy preserving federated learning in electronic health data. 2020 Presented at: 2020 IEEE International Conference on Blockchain (Blockchain); November 2-6, 2020; Rhodes, Greece. [doi: 10.1109/Blockchain50366.2020.00080]

3. Cheu A, Smith A, Ullman J, Zeber D, Zhilyaev M. Distributed Differential Privacy via Shuffling. In: Ishai Y, Rijmen V, editors. Advances in Cryptology - EUROCRYPT 2019. EUROCRYPT 2019. Lecture Notes in Computer Science, vol 11476. Cham: Springer; 2019:375-403.

4. Konečný J, McMahan HB, Yu FX, Richtárik P, Suresh AT, Bacon D. Federated Learning: Strategies for Improving Communication Efficiency. arXiv. 2016. URL: https://arxiv.org/abs/1610.05492 [accessed 2021-05-22]

5. Rieke N, Hancox J, Li W, Milletarì F, Roth HR, Albarqouni S, et al. The future of digital health with federated learning. NPJ Digit Med 2020 Sep 14;3(1):119-117 [FREE Full text] [doi: 10.1038/s41746-020-00323-1] [Medline: 33015372]

6. Tkachenko O, Weinert C, Schneider T, Hamacher K. Large-Scale Privacy-Preserving Statistical Computations for Distributed Genome-Wide Association Studies. In: ASIACCS '18: Proceedings of the 2018 Asia Conference on Computer and Communications Security. 2018 Presented at: 2018 Asia Conference on Computer and Communications Security; June 2018; Incheon, Republic of Korea p. 221-235. [doi: 10.1145/3196494.3196541]

7. Tomsett R, Chan K, Chakraborty S. Model poisoning attacks against distributed machine learning systems. In: Proceedings Volume 11006, Artificial Intelligence and Machine Learning for Multi-Domain Operations Applications. 2019 Presented at: Artificial Intelligence and Machine Learning for Multi-Domain Operations Applications; 2019; Baltimore, MD. [doi: $10.1117 / 12.2520275]$

8. Takabi D, Podschwadt R, Druce J, Wu C, Procopio K. Privacy preserving Neural Network Inference on Encrypted Data with GPUs. arXiv. 2019. URL: https://arxiv.org/abs/1911.11377 [accessed 2021-05-22]

9. Dahl M, Mancuso J, Dupis Y, Decoste B, Giraud M, Livingstone I, et al. Private Machine Learning in TensorFlow using Secure Computation. arXiv. 2018. URL: https://arxiv.org/abs/1810.08130 [accessed 2021-05-22]

10. Kaissis GA, Makowski MR, Rückert D, Braren RF. Secure, privacy-preserving and federated machine learning in medical imaging. Nat Mach Intell 2020 Jun 8;2(6):305-311. [doi: 10.1038/s42256-020-0186-1]

11. Salem M, Taheri S, Yuan J. Utilizing Transfer Learning and Homomorphic Encryption in a Privacy Preserving and Secure Biometric Recognition System. Computers 2018 Dec 29;8(1):3-24. [doi: 10.3390/computers8010003]

12. FitzHenry F, Resnic F, Robbins S, Denton J, Nookala L, Meeker D, et al. Creating a Common Data Model for Comparative Effectiveness with the Observational Medical Outcomes Partnership. Appl Clin Inform 2017 Dec 19;06(03):536-547. [doi: 10.4338/aci-2014-12-cr-0121]

13. Klann JG, Joss MAH, Embree K, Murphy SN. Data model harmonization for the All Of Us Research Program: Transforming i2b2 data into the OMOP common data model. PLoS One 2019 Feb 19;14(2):e0212463-e0212413 [FREE Full text] [doi: 10.1371/journal.pone.0212463] [Medline: 30779778]

14. Gujarathi G, Ma Y. Parametric CAD/CAE integration using a common data model. Journal of Manufacturing Systems 2011 Aug;30(3):118-132. [doi: 10.1016/j.jmsy.2011.01.002]

15. Saver JL, Warach S, Janis S, Odenkirchen J, Becker K, Benavente O, et al. Standardizing the Structure of Stroke Clinical and Epidemiologic Research Data. Stroke 2012 Apr;43(4):967-973. [doi: 10.1161/strokeaha.111.634352]

16. Overhage JM, Ryan PB, Reich CG, Hartzema AG, Stang PE. Validation of a common data model for active safety surveillance research. J Am Med Inform Assoc 2012 Jan 01;19(1):54-60 [FREE Full text] [doi: 10.1136/amiajnl-2011-000376] [Medline: 22037893]

17. Mamo L, Browe D, Logan H, Kim K. Patient informed governance of distributed research networks: results and discussion from six patient focus groups. AMIA Annu Symp Proc 2013;2013:920-929 [FREE Full text] [Medline: 24551383]

18. Hripcsak G, Duke JD, Shah NH, Reich CG, Huser V, Schuemie MJ, et al. Observational Health Data Sciences and Informatics (OHDSI): Opportunities for Observational Researchers. Stud Health Technol Inform 2015;216:574-578 [FREE Full text] [Medline: 26262116]

19. Data. The National Patient-Centered Clinical Research Network. URL: https://pcornet.org/data/ [accessed 2020-08-01]

20. Ji H, Kim S, Yi S, Hwang H, Kim J, Yoo S. Converting clinical document architecture documents to the common data model for incorporating health information exchange data in observational health studies: CDA to CDM. J Biomed Inform 2020 Jul;107:103459-103457. [doi: 10.1016/j.jbi.2020.103459] [Medline: 32470694]

21. Timbie J, Rudin R, Towe V, Chen E, Hunter L, Case S, et al. National Patient-Centered Clinical Research Network (PCORnet) Phase I: Final Evaluation Report. RAND. URL: https://www.rand.org/pubs/research_reports/RR1191.html [accessed 2021-05-22]

22. Martin-Sanchez FJ, Aguiar-Pulido V, Lopez-Campos GH, Peek N, Sacchi L. Secondary Use and Analysis of Big Data Collected for Patient Care. Yearb Med Inform 2017 Aug 19;26(01):28-37. [doi: 10.1055/s-0037-1606529] 
23. Zhang Y, Steele A, Blanton M. PICCO: a general-purpose compiler for private distributed computation. In: CCS '13: Proceedings of the 2013 ACM SIGSAC Conference on Computer \& Communications Security. 2013 Presented at: 2013 ACM SIGSAC Conference on Computer \& Communications Security; November 2013; Berlin, Germany p. 813-826. [doi: 10.1145/2508859.2516752]

24. Zhang Y, Blanton M, Almashaqbeh G. Secure distributed genome analysis for GWAS and sequence comparison computation. BMC Med Inform Decis Mak 2015 Dec 21;15(S5):1-12. [doi: 10.1186/1472-6947-15-s5-s4]

25. Dubovitskaya A, Urovi V, Vasirani M, Aberer K, Schumacher M. A Cloud-Based eHealth Architecture for Privacy Preserving Data Integration. In: Federrath H, Gollmann D, editors. ICT Systems Security and Privacy Protection. SEC 2015. IFIP Advances in Information and Communication Technology, vol 455. Cham: Springer; 2015:585-598.

26. Kho A, Cashy J, Jackson K, Pah A, Goel S, Boehnke J, et al. Design and implementation of a privacy preserving electronic health record linkage tool in Chicago. J Am Med Inform Assoc 2015 Sep;22(5):1072-1080 [FREE Full text] [doi:

10.1093/jamia/ocv038] [Medline: 26104741]

27. Huang L, Chu H, Lien C, Hsiao C, Kao T. Privacy preservation and information security protection for patients' portable electronic health records. Comput Biol Med 2009 Sep;39(9):743-750. [doi: 10.1016/j.compbiomed.2009.06.004] [Medline: 19589509]

28. Sahi MA, Abbas H, Saleem K, Yang X, Derhab A, Orgun MA, et al. Privacy Preservation in e-Healthcare Environments: State of the Art and Future Directions. IEEE Access 2018 Oct;6:464-478. [doi: 10.1109/access.2017.2767561]

29. Seol K, Kim Y, Lee E, Seo Y, Baik D. Privacy-Preserving Attribute-Based Access Control Model for XML-Based Electronic Health Record System. IEEE Access 2018 Feb 5;6:9114-9128. [doi: 10.1109/access.2018.2800288]

30. Blacketer C. Chapter 4 The Common Data Model. The Book of OHDSI. URL: https://ohdsi.github.io/TheBookOfOhdsi/ CommonDataModel.html [accessed 2020-08-01]

31. Lee S, You SC, Park J, Cho J, Borel S, El Emam K, et al. OMOP-CDM Conversion and Anonymization of National Health Insurance Service-National Sample Cohort. Observational Health Data Sciences and Informatics. 2019. URL: https://www. ohdsi.org/2019-us-symposium-showcase-17/ [accessed 2021-05-22]

32. Guidance Regarding Methods for De-identification of Protected Health Information in Accordance with the Health Insurance Portability and Accountability Act (HIPAA) Privacy Rule. U.S. Department of Health \& Human Services. 2015. URL: https://www.hhs.gov/hipaa/for-professionals/privacy/special-topics/de-identification/index.html [accessed 2020-08-01]

33. Wiley DC, Cory AC, editors. Health Insurance Portability and Accountability Act. In: Encyclopedia of School Health. Thousand Oaks, CA: SAGE Publications, Inc; 2013.

34. Murphy SN, Gainer V, Mendis M, Churchill S, Kohane I. Strategies for maintaining patient privacy in i2b2. J Am Med Inform Assoc 2011 Dec 01;18 Suppl 1(Supplement 1):i103-i108 [FREE Full text] [doi: 10.1136/amiajnl-2011-000316] [Medline: 21984588]

35. Li D. Data management system having a common database infrastructure. Google Patents. 2008. URL: https://patents. google.com/patent/US20040054675 [accessed 2021-05-22]

36. Olivier MS. Database privacy. SIGKDD Explor. Newsl 2002 Dec;4(2):20-27. [doi: 10.1145/772862.772866]

37. Blum A, Ligett K, Roth A. A learning theory approach to noninteractive database privacy. J. ACM 2013 Apr;60(2):1-25. [doi: $10.1145 / 2450142.2450148]$

38. Bergquist T, Brandt P. Prometheus: Differential Privacy in the OMOP CDM. University of Washington. 2018. URL: https:/ /courses.cs.washington.edu/courses/cse544/18wi/project/examples-successful-projects/psbrandt.pdf [accessed 2021-05-22]

39. Slavic A, Cordeiro M. Sharing and re-use of classification systems: the need for a common data model. The University of Arizona Libraries. 2005. URL: https://repository.arizona.edu/handle/10150/105132 [accessed 2021-05-22]

40. Makadia R, Ryan PB. Transforming the Premier Perspective Hospital Database into the Observational Medical Outcomes Partnership (OMOP) Common Data Model. EGEMS (Wash DC) 2014 Nov 11;2(1):1110-1110 [FREE Full text] [doi: 10.13063/2327-9214.1110] [Medline: 25848597]

41. Ganslandt T, Mate S, Helbing K, Sax U, Prokosch H. Unlocking Data for Clinical Research - The German i2b2 Experience. Appl Clin Inform 2017 Dec 16;02(01):116-117. [doi: 10.4338/aci-2010-09-cr-0051]

42. Liyanage H, Liaw S, Jonnagaddala J, Hinton W, de Lusignan S. Common Data Models (CDMs) to Enhance International Big Data Analytics: A Diabetes Use Case to Compare Three CDMs. Stud Health Technol Inform 2018;255:60-64. [Medline: 30306907]

43. Raisaro JL, Choi G, Pradervand S, Colsenet R, Jacquemont N, Rosat N, et al. Protecting Privacy and Security of Genomic Data in i2b2 With Homomorphic Encryption and Differential Privacy. IEEE/ACM Trans. Comput. Biol. and Bioinf 2018:1-1. [doi: 10.1109/tcbb.2018.2854782]

44. Sweeney L. k-anonymity: A model for protecting privacy. Int. J. Unc. Fuzz. Knowl. Based Syst 2012 May 02;10(05):557-570. [doi: 10.1142/s0218488502001648]

45. Machanavajjhala A, Gehrke J, Kifer D, Venkitasubramaniam M. L-diversity: privacy beyond k-anonymity. 2006 Presented at: 22nd International Conference on Data Engineering (ICDE'06); April 3-7, 2006; Atlanta, GA. [doi: 10.1109/icde.2006.1]

46. Li N, Li T, Venkatasubramanian S. t-Closeness: Privacy Beyond k-Anonymity and l-Diversity. 2007 Presented at: 2007 IEEE 23rd International Conference on Data Engineering; April 15-20, 2007; Istanbul, Turkey. [doi:

10.1109/icde.2007.367856] 
47. Shin SJ, You SC, Park YR, Roh J, Kim J, Haam S, et al. Genomic Common Data Model for Seamless Interoperation of Biomedical Data in Clinical Practice: Retrospective Study. J Med Internet Res 2019 Mar 26;21(3):e13249 [REEE Full text] [doi: 10.2196/13249] [Medline: 30912749]

48. OHDSI/CommonDataModel. GitHub. URL: https://github.com/OHDSI/CommonDataModel/wiki [accessed 2020-08-01]

49. CMS 2008-2010 Data Entrepreneurs' Synthetic Public Use File (DE-SynPUF). U.S. Centers for Medicare \& Medicaid Services. URL: https://www.cms.gov/Research-Statistics-Data-and-Systems/Downloadable-Public-Use-Files/SynPUFs/ DE_Syn_PUF [accessed 2020-08-01]

50. Data Standardization. Observational Health Data Sciences and Informatics. URL: https://ohdsi.org/data-standardization/ [accessed 2020-08-01]

51. OHDSI Google Drive. URL: https://drive.google.com/file/d/18EjMxyA6NsqBo9eed_Gab1ESHWPxJygz/view [accessed 2020-08-01]

52. El Emam K, Arbuckle L, Koru G, Eze B, Gaudette L, Neri E, et al. De-identification methods for open health data: the case of the Heritage Health Prize claims dataset. J Med Internet Res 2012 Feb 27;14(1):e33 [FREE Full text] [doi: 10.2196/jmir.2001] [Medline: 22370452]

53. Gong M, Wang S, Wang L, Liu C, Wang J, Guo Q, et al. Evaluation of Privacy Risks of Patients' Data in China: Case Study. JMIR Med Inform 2020 Feb 05;8(2):e13046 [FREE Full text] [doi: 10.2196/13046] [Medline: 32022691]

54. Benitez K, Malin K. Evaluating re-identification risks with respect to the HIPAA privacy rule. J Am Med Inform Assoc 2010;17(2):169-177 [FREE Full text] [doi: 10.1136/jamia.2009.000026] [Medline: 20190059]

55. Garfinkel SL. De-Identification of Personal Information. National Institute of Standards and Technology. 2015. URL: https://nvlpubs.nist.gov/nistpubs/ir/2015/NIST.IR.8053.pdf [accessed 2021-05-17]

56. Committee on Strategies for Responsible Sharing of Clinical Trial Data, Board on Health Sciences Policy, Institute of Medicine. Concepts and Methods for De-identifying Clinical Trial Data. In: Sharing Clinical Trial Data: Maximizing Benefits, Minimizing Risk. Washington, DC: National Academies Press (US); 2015.

57. Lee YJ, Lee KH. What are the optimum quasi-identifiers to re-identify medical records? 2018 Presented at: 20th International Conference on Advanced Communication Technology (ICACT); February 11-14, 2018; Chuncheon, Korea (South). [doi: $10.23919 /$ icact.2018.8323926]

58. Definition and DDLs for the OMOP Common Data Model (CDM). GitHub. URL: https://github.com/OHDSI/ CommonDataModel/tree/v5.2.2 [accessed 2020-08-01]

59. Zhou X, Murugesan S, Bhullar H, Liu Q, Cai B, Wentworth C, et al. An evaluation of the THIN database in the OMOP Common Data Model for active drug safety surveillance. Drug Saf 2013 Feb 4;36(2):119-134. [doi: 10.1007/s40264-012-0009-3] [Medline: 23329543]

60. Si Y, Weng C. An OMOP CDM-Based Relational Database of Clinical Research Eligibility Criteria. Stud Health Technol Inform 2017;245:950-954 [FREE Full text] [Medline: 29295240]

61. Glicksberg B, Oskotsky B, Thangaraj P, Giangreco N, Badgeley M, Johnson K, et al. PatientExploreR: an extensible application for dynamic visualization of patient clinical history from electronic health records in the OMOP common data model. Bioinformatics 2019 Nov 01;35(21):4515-4518 [FREE Full text] [doi: 10.1093/bioinformatics/btz409] [Medline: 31214700]

62. Karr AF, Feng J, Lin X, Sanil AP, Young SS, Reiter JP. Secure analysis of distributed chemical databases without data integration. J Comput Aided Mol Des 2005 Nov 3;19(9-10):739-747. [doi: 10.1007/s10822-005-9011-5] [Medline: 16267693]

63. Domingo-Ferrer J. Microaggregation for Database and Location Privacy. In: Etzion O, Kuflik T, Motro A, editors. Next Generation Information Technologies and Systems. NGITS 2006. Lecture Notes in Computer Science, vol 4032. Berlin, Heidelberg: Springer; 2006:106-116.

64. Raab M, Steger A. "Balls into Bins" - A Simple and Tight Analysis. In: Luby M, Rolim JDP, Serna M, editors. Randomization and Approximation Techniques in Computer Science. RANDOM 1998. Lecture Notes in Computer Science, vol 1518. Berlin, Heidelberg: Springer; 1998:159-170.

65. Shin S, Park YR, Shin Y, Choi HJ, Park J, Lyu Y, et al. A De-identification method for bilingual clinical texts of various note types. J Korean Med Sci 2015 Jan;30(1):7-15 [FREE Full text] [doi: 10.3346/jkms.2015.30.1.7] [Medline: 25552878]

66. Abdalla M, Abdalla M, Rudzicz F, Hirst G. Using word embeddings to improve the privacy of clinical notes. J Am Med Inform Assoc 2020 Jun 01;27(6):901-907 [FREE Full text] [doi: 10.1093/jamia/ocaa038] [Medline: 32388549]

\section{Abbreviations}

CDM: common data model

DRN: distributed research network

EC: equivalence class

HIPAA: Health Insurance Portability and Accountability Act

NPI: national provider identifier

OHDSI: Observational Health Data Sciences and Informatics

OMOP: Observational Medical Outcome Partnership 
PHI: personal health identifier

QI: quasi-identifier

SynPUF5PCT: Synthetic Public Use File 5 Percent

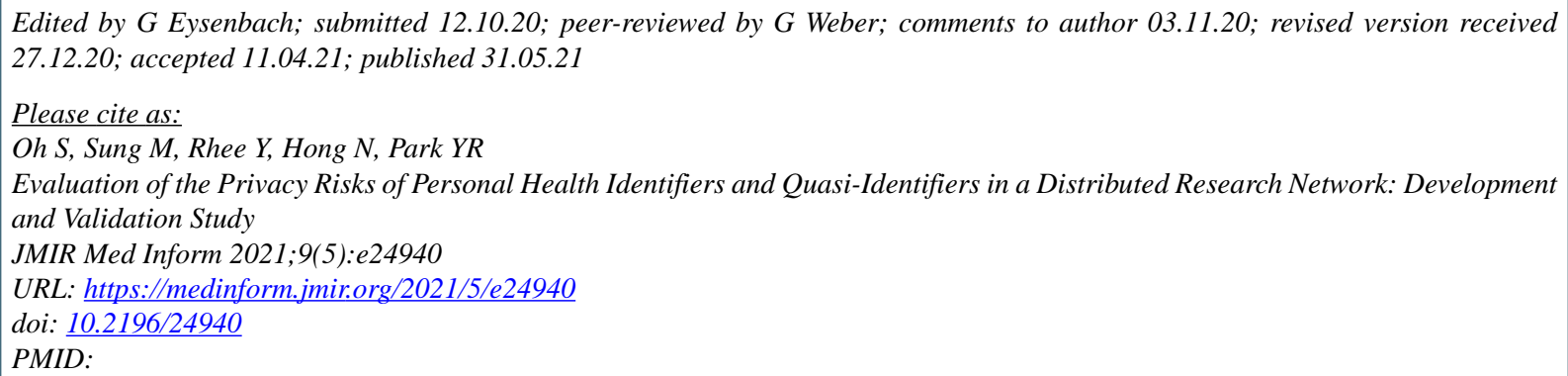

CSeHee Oh, MinDong Sung, Yumie Rhee, Namki Hong, Yu Rang Park. Originally published in JMIR Medical Informatics (https://medinform.jmir.org), 31.05.2021. This is an open-access article distributed under the terms of the Creative Commons Attribution License (https://creativecommons.org/licenses/by/4.0/), which permits unrestricted use, distribution, and reproduction in any medium, provided the original work, first published in JMIR Medical Informatics, is properly cited. The complete bibliographic information, a link to the original publication on https://medinform.jmir.org/, as well as this copyright and license information must be included. 